\title{
Laser Welding of Grey Cast Iron with Spheroidal Graphite-Influence of Process Parameters on Crack Formation and Hardness
}

\author{
Niklas Sommer * ${ }^{\mathbb{D}}$, John Michael Lehto, Stephan Völkers and Stefan Böhm
}

check for updates

Citation: Sommer, N.; Lehto, J.M.; Völkers, S.; Böhm, S. Laser Welding of Grey Cast Iron with Spheroidal Graphite-Influence of Process Parameters on Crack Formation and Hardness. Metals 2021, 11, 532. https://doi.org/10.3390/met11040532

Academic Editor: Paolo Ferro

Received: 9 March 2021

Accepted: 20 March 2021

Published: 24 March 2021

Publisher's Note: MDPI stays neutral with regard to jurisdictional claims in published maps and institutional affiliations.

Copyright: (c) 2021 by the authors. Licensee MDPI, Basel, Switzerland. This article is an open access article distributed under the terms and conditions of the Creative Commons Attribution (CC BY) license (https:// creativecommons.org/licenses/by/ $4.0 /)$.
Department for Cutting and Joining Manufacturing Processes, Institute for Production Technologies and Logistics, University of Kassel, Kurt-Wolters-Straße 3, 34125 Kassel, Germany; john.lehto@uni-kassel.de (J.M.L.); s.voelkers@uni-kassel.de (S.V.); s.boehm@uni-kassel.de (S.B.)

* Correspondence: n.sommer@uni-kassel.de

\begin{abstract}
In the investigation at hand, sheets of ferritic and pearlitic grey cast iron with spheroidal graphite are welded using a fiber-laser. The influence of varying laser power and welding speed on the macroscopic characteristics of the weld seam and crack formation are analyzed and discussed. Substantial crack formation with crack densities of up to $2.93 \mathrm{~cm}^{-1}$ are found. Furthermore, hardness measurements are conducted to evaluate the formation of brittle phases within the weld metal and heat-affected zone. Peak hardness values of up to $860 \mathrm{HV} 0.3$ and 975 HV0.3 are identified in EN-GJS-400-15 and EN-GJS-700-2, respectively. Subsequently, a proposition on the dependence of crack formation on weld seam width is given. Furthermore, the influence of nickel-containing filler material on the microstructure, crack formation and hardness is studied. It can be derived from the results that laser-beam welding of grey cast iron with spheroidal graphite requires further research in order to achieve crack-free weld seams and hinder the formation of undesirable, brittle phases.
\end{abstract}

Keywords: laser welding; cast iron; spheroidal graphite; spheroidal graphite cast iron; nodular cast iron; microstructure; microstructural evolution; mechanical properties; crack formation; cold cracking

\section{Introduction}

In light of rising efforts to combat climate change, new practices must be implemented to reduce emissions and increase energy efficiency. In manufacturing, this can be achieved through substantial weight savings of components. Due to its lower density and, thus, decreased weight of components, grey cast iron was found to be a suitable alternative to substitute steel in a variety of applications. One cast iron type of increasing importance is cast iron with spheroidal graphite. The advantages are its high tensile strength while simultaneously offering high ductility, its high recyclability, and its good machinability. As an alternative to steel, cast iron with spheroidal graphite is used for crankshafts, differential gears, housing parts, and pinions in automobile manufacturing [1].

Unlike low carbon steels, however, cast iron with spheroidal graphite features poor weldability properties. Reliance on bolted connections is common because during welding, high carbon contents promote the growth of hard and brittle microstructures such as martensite and ledeburite [2]. The impact of these microstructures is seen in the reduction of tensile strength and loss of ductility. Furthermore, the welded joint is susceptible to cracking in the weld metal (WM) and heat affected zone (HAZ), not only due to brittle phases but also as a result of hydrogen embrittlement, as it was recently published for bulk EN-GJS-400-15 by Forsström et al. [3] and Sahiluoma et al. [4]. Previous research considered different measures to improve weldability in shielded arc metal welding. Firstly, AskariPaykani et al. [5] reported that the recovery of some of the original mechanical properties could be achieved by preheating to $300^{\circ} \mathrm{C}$, while Voigt and Loper [6] investigated the effects of post-weld heat treatments (PWHT) and found that martensite formed during 
welding was decomposed after an annealing at $900^{\circ} \mathrm{C}$ for two hours. Thus, the hardness and tensile strength of the base material could be recovered, but-on the other handtoughness and ductility of the base material were not regained. Pascual et al. [7] used filler wire with high nickel content and found that the achieved results were superior to weldments with grey iron filler material as the joints exhibited increased ductility.

Because higher welding velocities result in higher productivity, laser and electron beam welding are among processes increasingly used in industrial applications. The challenge of avoiding hard and brittle microstructures is exacerbated due to high cooling rates associated with the aforementioned welding processes [2].

Several researchers have discussed the phenomena during beam welding of grey cast iron with spheroidal graphite and proposed procedures for improved weldability in similar and dissimilar welds [8-14]. Rüthrich et al. investigated the influence of an in situ heat treatment using an electron beam. Through the utilization of an integrated heat treatment during electron beam welding of grey cast iron, they reported a significant reduction of crack density, pores and hardness increase within the WM and HAZ [8-10]. With a focus on laser beam welding (LBW), Bünting and Francke investigated the use of high-brilliance beam sources to join dissimilar welds of grey cast iron and case-hardened steel. They found that active control of the laser beams position within the seam geometry enabled a reproducible adaption of mixture ratio between iron and steel with decreased spatter formation [11]. Yu et al. focused on the industrial application of grey cast iron and studied the weldability of differential gears made from grey cast iron and carburized steel using a $\mathrm{CO}_{2}$-laser and nickel-containing filler material [12]. While cracks were found within some of the cross-sections, the overall performance of the welded part was superior to the bolted connection [12]. In order to manipulate the thermal cycle during welding, Vollmer et al. [13] used electromagnetic induction to impose pre- and post heat-treatment on grey cast iron specimens welded by fiber-laser and reported a reduction of crack formation as well as hardness. In continuance of this approach, Saffer et al. studied the capabilities of a defocused laser beam to enable a pre- and post heat-treatment of the weld seam during LBW and reported a reduction of hardness [14].

Other than LBW, multiple research efforts with a focus on enhanced erosion resistance of grey cast iron with spheroidal graphite through laser surface melting have been made, e.g., by Janicki $[15,16]$. It was found that surface melting of nodular grey cast iron yielded hardness values of up to $1000 \mathrm{HV}$ in non-porous layers. Yet, some samples showed the formation of cracks [15]. Additionally, experiments on laser surface alloying of nodular grey cast iron were conducted with chromium-powder by Janicki [17] for improved abrasion resistance. The experiments enabled the fabrication of uniformly alloyed surface layers with up to $14.4 \mathrm{wt} \%$ of chromium [17].

As can be derived from the study of literature above, multiple efforts have been made to enable LBW of grey cast iron. Yet, different beam sources, filler materials and heat treatments were used and published. Therefore, the authors of the present publication seek to systematically investigate the influence of process parameters on the microstructural evolution, crack formation and hardness of grey cast iron during LBW.

\section{Materials and Methods}

\subsection{Materials and Process Setup}

In the investigation at hand, two types of grey cast iron with speroidal graphite, EN-GJS-400-15 and EN-GJS-700-2, were analyzed. While EN-GJS-400-15 featured a ferritic microstructure, EN-GJS-700-2 mainly showed a pearlitic solidification mode (cf. Figure 1). The chemical composition of the two materials is to be found in Table 1. 
Table 1. Chemical composition of EN-GJS-400-15 and EN-GJS-700-2 used in the present investigation, in wt.\%. Provided by material supplier.

\begin{tabular}{lcccccc}
\hline Alloy & C & Si & Mn & P & S & Fe \\
\hline EN-GJS-400-15 & 3.5 & 2.1 & 0.2 & 0.04 & 0.01 & bal. \\
EN-GJS-700-2 & 3.5 & 2.0 & 0.25 & 0.04 & 0.01 & bal. \\
\hline
\end{tabular}

For the welding experiments, sheets of $300 \mathrm{~mm} \times 100 \mathrm{~mm} \times 5 \mathrm{~mm}$ were fixed in buttjoint configuration by holding-down clamps and counterholders. The abutting edges of the sheets were milled to achieve a joint configuration of increased repeatability and quality.
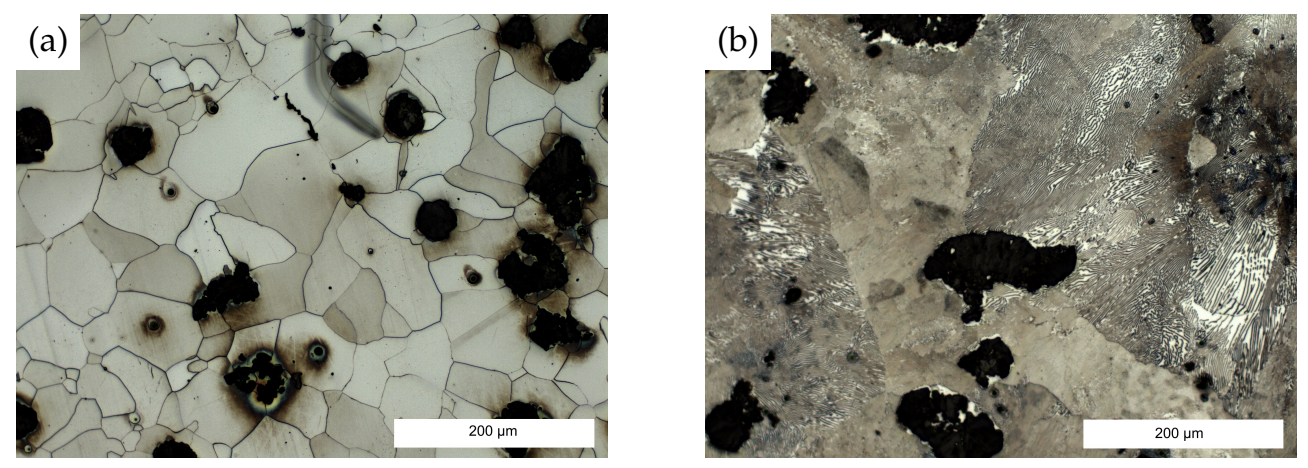

Figure 1. Microstructure of as-received grey cast iron with speroidal graphite. (a) ferritic EN-GJS400-15, (b) pearlitic EN-GJS-700-2.

The feed motion of the welding experiments was realized through a three-axis robot (KUKA Industries GmbH \& Co. KG, Obernburg, Germany) with modular processing optics (Reis Lasertec MWO54, KUKA Industries GmbH \& Co. KG, Aachen, Germany) attached to it. A $10 \mathrm{~kW}$ fiber-laser (IPG YLS-10000-S4, IPG Laser GmbH, Burbach, Germany) with a wavelength of $1070 \mathrm{~nm}$ and a top-hat intensity profile was used as beam source, whose beam was guided to the processing optics using a fiber with a diameter of $200 \mu \mathrm{m}$. The use of a lens with a focal length of $300 \mathrm{~mm}$ yielded an approximate beam diameter of $0.4 \mathrm{~mm}$ on the workpiece, while the focal offset $z_{f}$ was set to $0 \mathrm{~mm}$, meaning that the beam was focused on top of the workpiece. To prevent oxidation of the weld seam during welding, Argon shielding gas (grade 4.6, purity $\geq 99.996 \%$ ) was fed to the process zone using a nozzle adapted to the welding optics. In consideration of the laser beam area $A_{L}$, derived from its diameter mentioned above, the intensity $I_{L}$ of the laser beam could be calculated as

$$
I_{L}=\frac{P_{L}}{A_{L}}
$$

which was deduced from [18]. For all laser powers given in the experimental design, the intensity is $I_{L} \geq 1 \times 10^{6} \mathrm{~W} \mathrm{~cm}^{-1}$, which proves that the welding process was conducted in the regime of deep penetration welding [19].

To allow for a thorough analysis of the impact of process parameters on the microstructural evolution, crack formation and hardness, an experimental design with three different laser power settings $P_{L}$ at five different welding speeds $v_{L}$ was employed. It was assumed that the energy input $E_{L}$ required for through penetration welding ought to be characterized by a linear decrease with an increase in welding speed. Based on this assumption, different energy inputs and, thus, laser powers were calculated from preliminary investigations on through penetration welding of the sheet material using Equation (2). The equation was computed by the authors based on a linear regression on the results of through penetration welding at different welding speeds.

$$
E_{L}\left(v_{L}\right)=-100.12 \times v_{L}+410.76
$$


Using the calculated mean value of energy input, two additional values of energy input were computed from it with an increase and decrease of $10 \%$ in energy input for each welding speed. Hereinafter, the laser power $P_{L}$ is calculated as

$$
P_{L}=E_{L} \times v_{L}
$$

The experimental design established based on these calculations is to be found in Table 2 .

Table 2. Experimental design employed during the present investigation.

\begin{tabular}{lccccc}
\hline & \multicolumn{4}{c}{ Welding Speed $\left[\mathbf{m ~ m i n}^{-\mathbf{1}}\right]$} \\
& $\mathbf{0 . 5}$ & $\mathbf{1 . 0}$ & $\mathbf{1 . 5}$ & $\mathbf{2 . 0}$ & $\mathbf{2 . 5}$ \\
\hline \multirow{2}{*}{ Laser Power } & 2700 & 4700 & 5900 & 6300 & 6000 \\
{$[\mathrm{~W}]$} & 3000 & 5200 & 6500 & 7000 & 6700 \\
& 3300 & 5700 & 7200 & 7700 & 7400 \\
\hline
\end{tabular}

An approach to tackle crack formation in laser-welded joints of grey cast iron with spheroidal graphite is the use of filler material with high nickel content, as it was proposed by $\mathrm{Yu}$ et al. [12]. In order to analyze the microstructural evolution, crack formation and hardness of such an approach, both materials were welded with nickel filler material (purity $>99.7 \%$, thicknesses $t_{1}=0.125 \mathrm{~mm}$ and $t_{2}=0.250 \mathrm{~mm}$ ) in form of a foil that was inserted between the two sheets at the abutting edges. These additional experiments were conducted at a constant welding speed of $2.5 \mathrm{~m} \mathrm{~min}^{-1}$ and a laser power of $6000 \mathrm{~W}$ for the sake of comparison to previous results.

\subsection{Microstructural Characterization and Hardness Testing}

Following the welding experiments, the formation of cracks perpendicular to the welding direction on the top of the weld seam was investigated using a non-destructive dye penetrant test in accordance to DIN EN ISO 3452-1 [20]. Based on these observations, the cracking density $R$ was calculated as

$$
R=\frac{n_{R}}{l}
$$

where $n_{R}$ describes the number of cracks and $l$ the weld seam length. To allow for a characterization of the microstructural evolution within the weld seams, polished and etched cross-sections were characterized using optical microscopy (OM; DM2700, Leica Microsystems $\mathrm{GmbH}$, Wetzlar, Germany). The samples were etched with $\mathrm{Nital}\left(3 \% \mathrm{HNO}_{3}\right.$, $\left.97 \% \mathrm{C}_{2} \mathrm{H}_{5} \mathrm{OH}\right)$. Vickers hardness testing was conducted on the basis of DIN EN ISO 6507-1 [21] using an automated hardness-testing machine (KB30, KB Prüftechnik GmbH, Hochdorf-Assenheim, Germany) with a force of $2.942 \mathrm{~N}$ (HV0.3) for samples welded without filler material and $0.9807 \mathrm{~N}$ (HV0.1) for samples welded with filler material.

\section{Results and Discussion}

\subsection{Microstructural Evolution, Crack Formation and Hardness Measurements}

The welding process proved to be characterized by pronounced spatter formation for all laser power and welding speed settings applied, which can be attributed to the comparatively high carbon-content of the materials. As was expected from the literature study on high-energy beam welding of grey cast iron, substantial crack formation in both, EN-GJS-400-15 and EN-GJS-700-2, could be observed. Even more so, none of the samples could be welded crack-free. As can be derived from Figure 2, the crack density increased almost linearly for both materials with an increase in welding speed. 
(a)

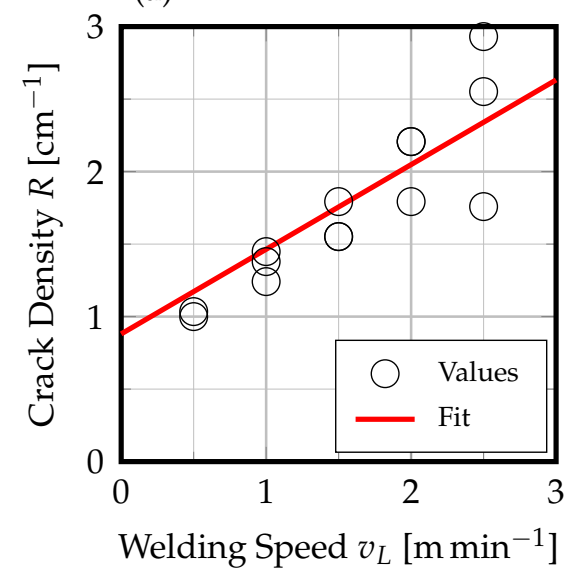

(b)

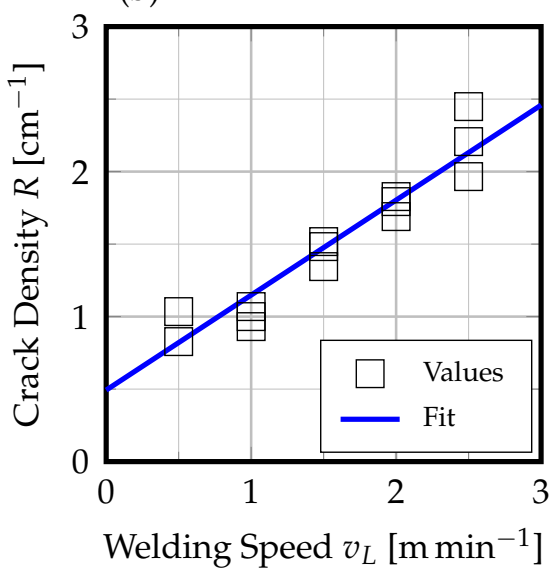

Figure 2. Crack density $R$ plotted versus welding speed $v_{L}$ for (a) EN-GJS-400-15 and (b) EN-GJS700-2.

Notably, the formation of cracks dominantly occurred after the welding process during cooling, which could be perceived by acoustic emissions from the weld seam. This observation led to the conclusion that cold-cracking below the liquidus of the material was the dominant mechanism involved. As cold-cracking can mainly be attributed to low ductility of weld metal and residual stress, it was assumed that brittle phases must have formed during LBW. Moreover, based on the results in Figure 2 it was supposed that higher welding speeds led to more rapid solidification and steeper thermal gradients within the welding zone, hence promoting crack formation. To allow for a thorough analysis of these propositions, a characterization of the microstructural evolution was necessary, which shall be discussed in further detail in the following paragraphs.

The macroscopic images of polished and etched cross-sections of the weld seams obtained by LBW are to be found in Figure 3. For the sake of clarity and comparison, welding speeds of $1.0 \mathrm{~m} \mathrm{~min}^{-1}$ and $2.5 \mathrm{~m} \mathrm{~min}^{-1}$ are shown and discussed in further detail.

As it was assumed in the preceding paragraph, the weld seams of both materials and welding speeds were characterized by a microstructural transformation and grain growth towards the abutting edges. Moreover, the strong reaction of the etchant Nital, shown as dark coloring of the weld seam, indicated the presence of large amounts of carbon in solid solution. This was supported by the fact that no spheroidal graphite was found within the weld metal. When looking at the macroscopic characteristics of the weldments presented, it was evident that the weld seam width of both materials was drastically smaller at higher welding speeds than at lower welding speeds. While the slower welding speed yielded a vase-like weld seam structure, it was narrower and I-shaped in case of higher welding speeds. In order to quantify this observation, measurements of all weld seam widths at the distinct locations top, waist and root were taken and plotted versus the welding speed, as can be seen in Figure 4a,b. From these results, it was evident that the weld seam width at all measured locations was decreased with an increase in welding speed. Notably, an exponential fit of the mean width values at the top of the weld seam, depicted in Figure $4 \mathrm{c}, \mathrm{d}$, almost ideally represents these observations with coefficients of determination $R^{2}$ of 0.8247 and 0.9625 for EN-GJS-400-15 and EN-GJS-700-2, respectively.

These results can be attributed to varying thermal regimes present within the weld seam at different welding speeds. While at low welding speeds, pronounced heat conduction from the molten material to the adjacent regions takes place, this is effect is somewhat mitigated at higher welding speeds, when the lasers interaction time per unit volume is reduced. Hence, the melt pool and, subsequently, the weld seam width and width of HAZ are enlarged at lower welding speeds.

As an increase of welding speed directly corresponds to reduced cycle times and, thus, enhanced productivity in industrial applications, certain areas of interest (AOIs) within the 
cross-sections welded at welding speeds of $2.5 \mathrm{~m} \mathrm{~min}^{-1}$ were investigated in further detail with regard to their microstructural evolution. These results are to be found in Figure 5 .
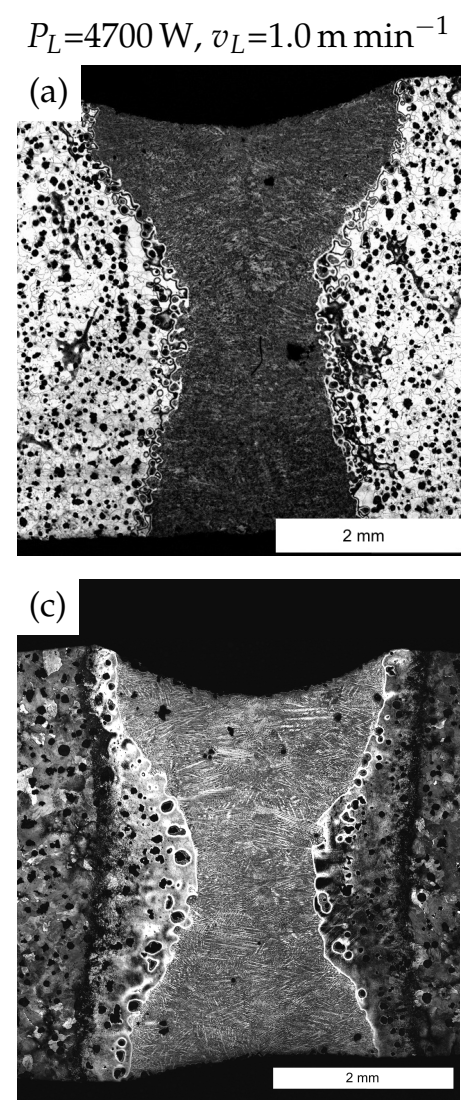
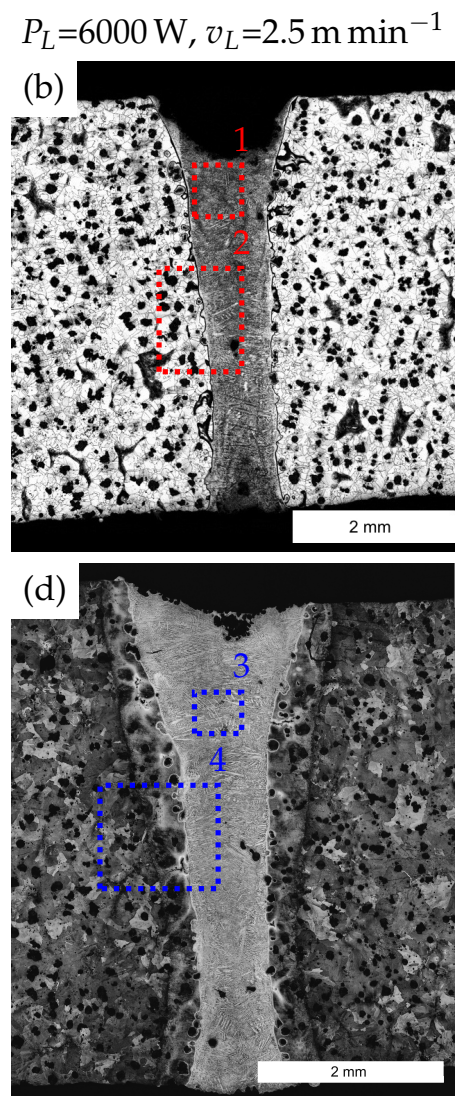

Figure 3. Macroscopic images of laser-welded grey cast iron with spheroidal graphite. (a,b) EN-GJS400-15, (c,d) EN-GJS-700-2. Areas of interest highlighted for further microscopic investigation, which is to be found in Figure 5.

The strong reaction of the etchant and absence of spheroidal graphite suggested large amounts of carbon in solid solution within the weld metal (WM). As can be derived from Figure 5 (1) and (3), an analysis of the microstructure within the weld metal identified the formation of ledeburite. This phase mixture is known to be hard and brittle due to its constituent cementite, which could be identified in a lath-formed structure with surrounding martensite for both materials investigated. In the HAZ, however, the microstructural evolution was different for both materials. In EN-GJS-400-15, the transition from weld metal to unaffected, ferritic material was sharp. The HAZ was characterized by a seam with a width of approximately $30 \mu \mathrm{m}$ adjacent to the fusion line. The dark coloring of the seams outside is an indication of carburization due to thermally activated diffusion processes during LBW. These observations affirm the results of Rüthrich [10], who found similar microstructural features upon electron beam welding of grey cast iron with spheroidal graphite. 
(a)

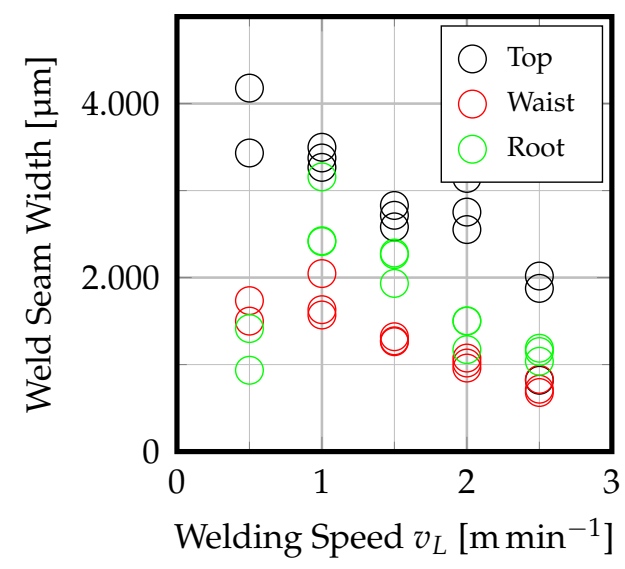

(c)

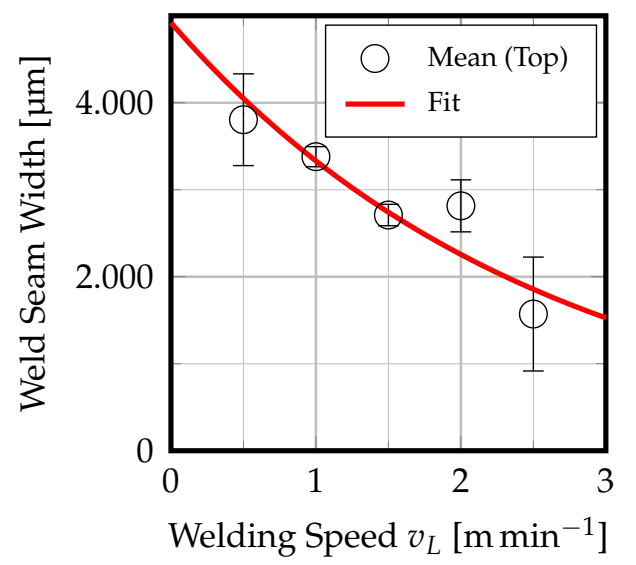

(b)

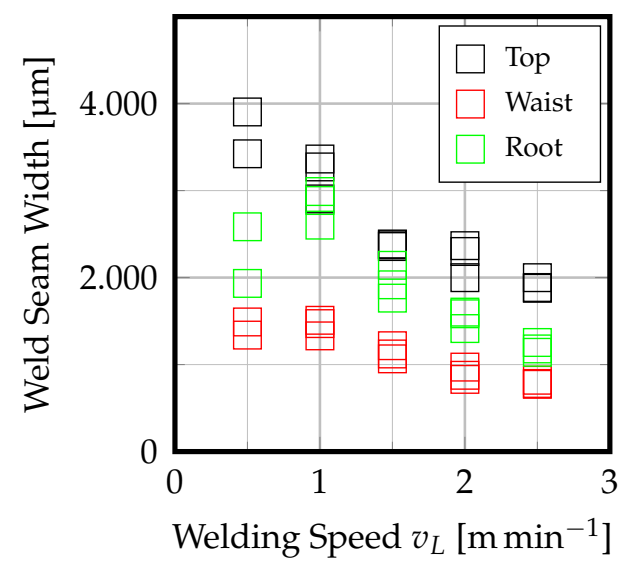

(d)

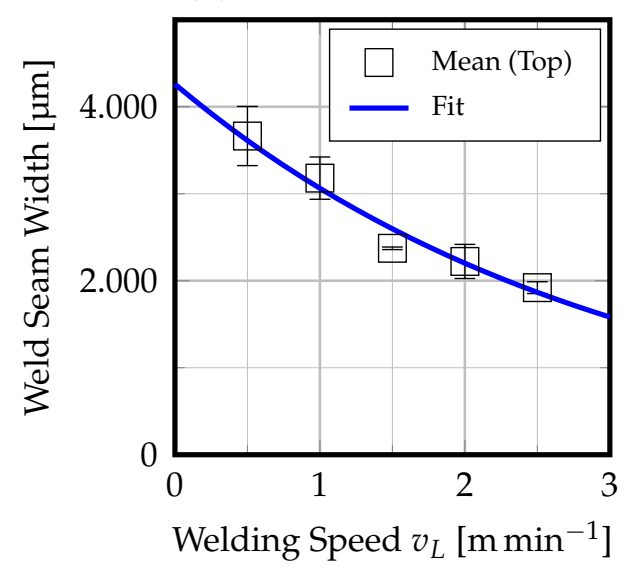

Figure 4. Weld seam widths obtained at different locations within the samples of (a) EN-GJS-40015, (b) EN-GJS-700-2. Mean values of weld seam width at the seam top with corresponding fits, (c) EN-GJS-400-15, (d) EN-GJS-700-2. Error bars represent standard error of the mean (SEM).

Yet, when the HAZ of EN-GJS-700-2 was analyzed, different features could be observed. Firstly, the HAZ extended over a far larger scale of approximately $400 \mu \mathrm{m}$. Moreover, inclusions of spheroidal graphite could be found within the HAZ that were accumulated to clusters and the microstructure close to the fusion line was transformed to fine laths of martensite with different orientations. Close to the unaffected parent material, a seam of precipitates-possibly $\mathrm{Fe}_{3} \mathrm{C}$ - was to be found within a bainitic microstructure. The microstructural transformation of the HAZ as well as the presence of precpitations close to the parent material can be explained by thermally induced transformation processes. As the maximum temperature experienced during the weld cycle increases toward the fusion line, carbon was kept in solid solution during the rapid cooling after welding and enabled a martensitic transformation. Nevertheless, as the maximum temperature decreases toward the unaffected material, the tranformation to bainite and precipitation of excess carbon were enabled. Moreover, the nodular graphite within the HAZ was surrounded by a structure of fine martensite-laths, which was also found by Janicki [17] during laser surface melting of grey cast iron with spheroidal graphite. 
WM
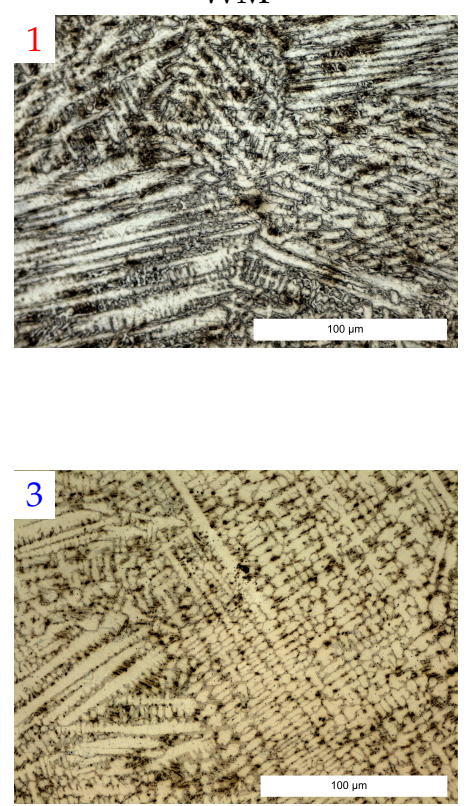

HAZ
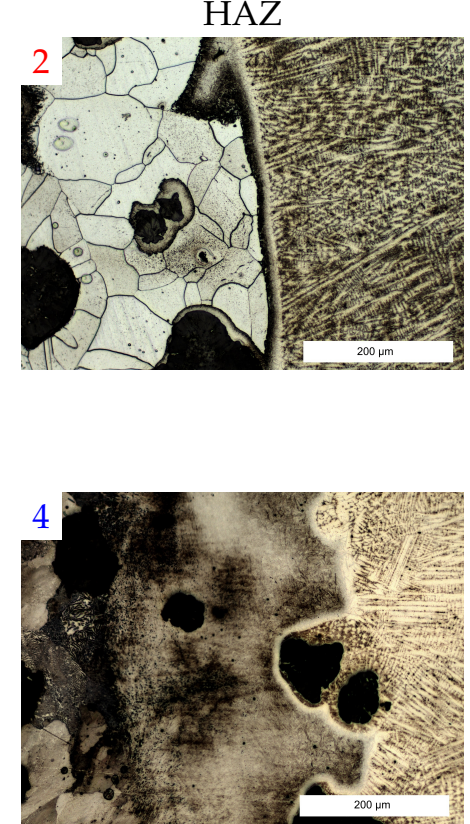

Figure 5. Microscopy images of laser-welded grey cast iron with spheroidal graphite. $(\mathbf{1}, \mathbf{2}) \mathrm{EN}$ GJS-400-15, $(3,4)$ EN-GJS-700-2. $P_{L}=6000 \mathrm{~W}, v_{L}=2.5 \mathrm{~m} \mathrm{~min}^{-1}$. Designation with reference to AOIs marked in Figure 3.

As the microstructural transformations within the weld seam and HAZ impose significant changes to the mechanical properties of the material, these shall be analyzed by an investigation of hardness in the following paragraph.

The analysis of hardness confirmed the propositions made in the preceding section. For both materials, a drastic increase in hardness could be observed, which was plotted versus the welding speed in Figure 6a,c. Yet, for EN-GJS-400-15, no systematic influence of welding speed on peak hardness could be identified. On the other hand, the peak hardness of EN-GJS-700-2 was characterized by a slight decrease with increasing welding speed. It is to be noted, however, that the hardness distributions of the two materials and welding speeds shown in Figure 6b,d differed substantially.

Firstly, as it was expected from the macroscopic investigation of the weld seams in Figure 3, the zone of hardness increase was larger for a welding speed of $1.0 \mathrm{~m} \mathrm{~min}^{-1}$ than for $2.5 \mathrm{~m} \mathrm{~min}^{-1}$. This observation can be ascribed to the evolution of the weld seam width as it was discussed before. Yet, when comparing the results of EN-GJS-400-15 and EN-GJS-700-2, a drastic difference in width of hardness increase could be identified. Whereas EN-GJS-400-15, welded at a speed of $2.5 \mathrm{~m} \mathrm{~min}^{-1}$, reached hardness values of the unaffected base material approximately $-0.75 \mathrm{~mm}$ from the weld center, EN-GJS-700-2 was characterized by a hardness of up to $850 \mathrm{HV}$ in the same region. This phenomenon can be attributed to the larger HAZ of EN-GJS-700-2 and the martensitic microstructure within. Furthermore, it can be confirmed that the sharp microstructural transition from WM to unaffected base material in EN-GJS-400-15 yielded a narrower zone of hardness increase and a steeper transition. 
(a)

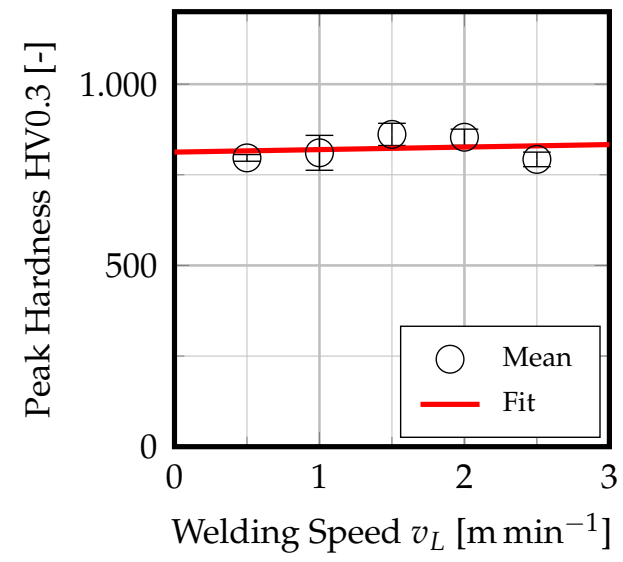

(c)

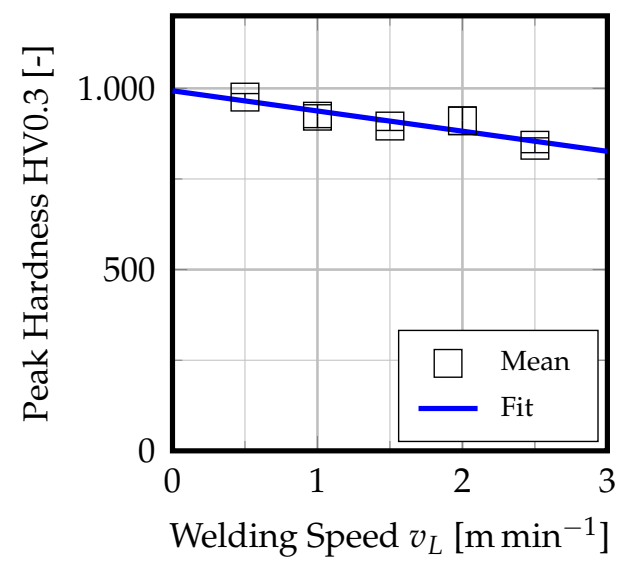

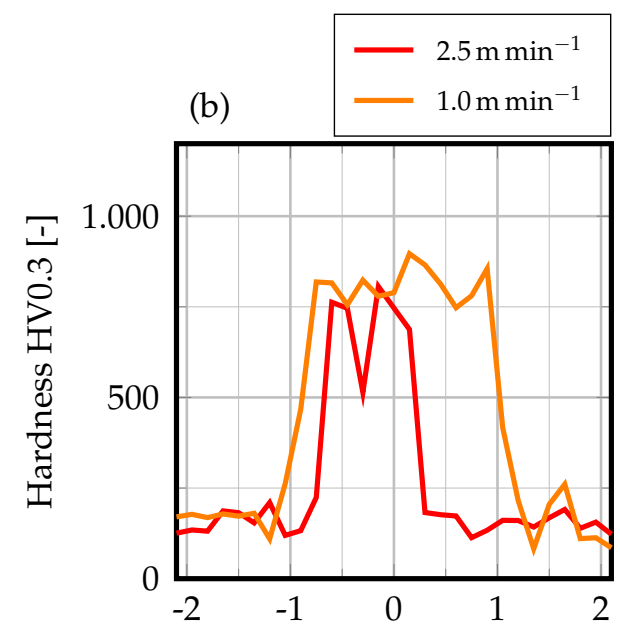

Distance from Weld Center [mm]

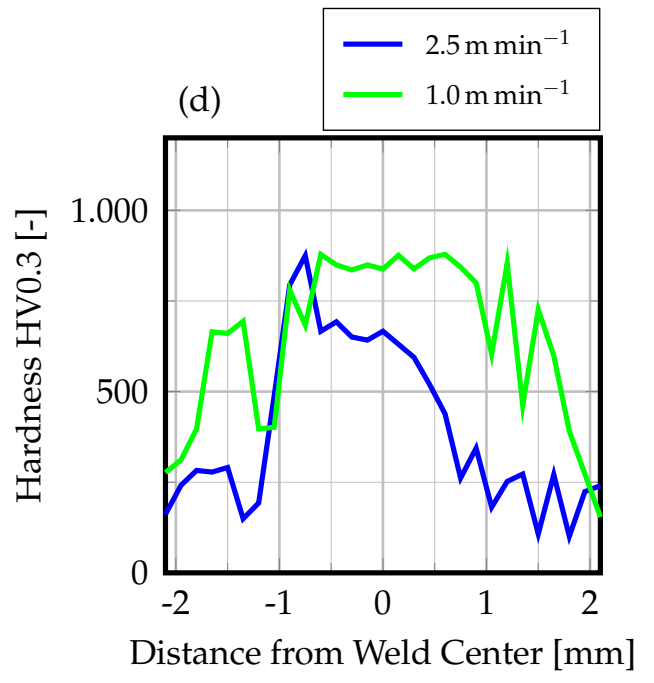

Figure 6. Mean values of peak hardness plotted versus welding speed $v_{L}$ as well as hardness distribution for different welding speeds $v_{L}$ for $(\mathbf{a}, \mathbf{b})$ EN-GJS-400-15 and (c,d) EN-GJS-700-2. Error bars represent SEM.

As different hardness distributions could be obtained for varying welding speeds, it was to be investigated if these variations had an influence on the crack density that was discussed in the preceding section. Thus, the results of the crack density measurements were plotted versus the peak hardness of the samples, which are presented in Figure 7a,b. Yet, the plots demonstrated contrary results for EN-GJS-400-15 and EN-GJS-700-2 which indicated that the peak hardness of the samples did not pose a systematic influence on crack density. In search of the causes for an increased crack density at high welding speeds, the varying weld seam width at different welding speeds came into the foreground of the investigation. As a result, the weld seam width at the top of the seam and the crack density were plotted in Figure 7c,d. 
(a)

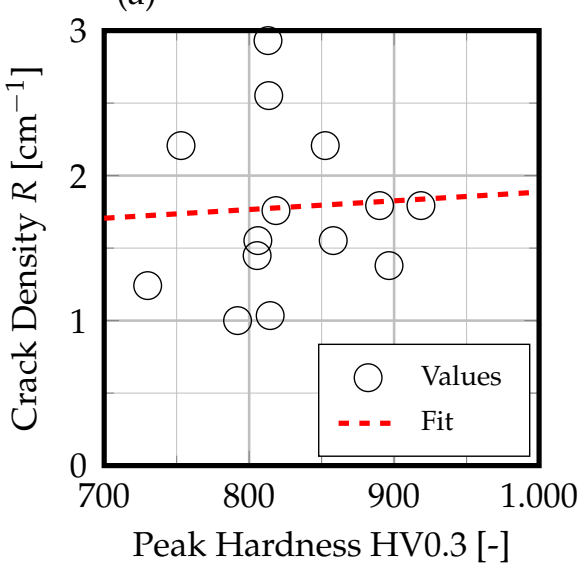

(c)

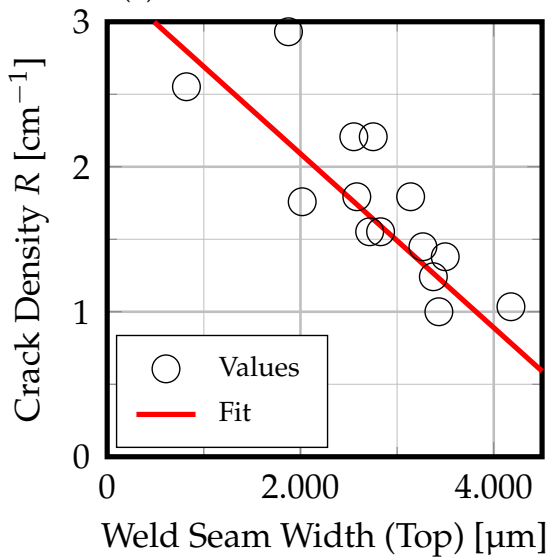

(b)

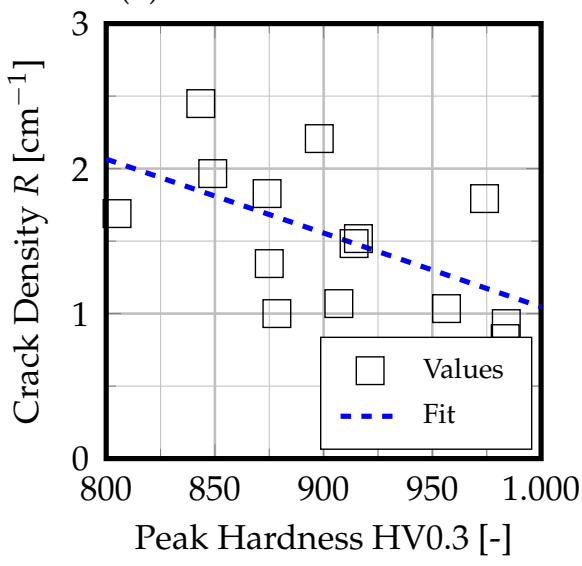

(d)

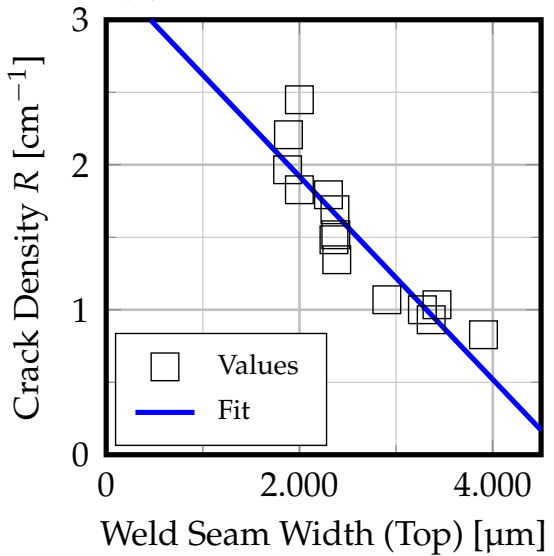

Figure 7. Crack density $R$ plotted versus $(\mathbf{a}, \mathbf{b})$ peak hardness and $(\mathbf{c}, \mathbf{d})$ weld seam width on seam top. Left: EN-GJS-400-15, right: EN-GJS-700-2.

As can be derived from the values and linear fits, the weld seam width did exhibit a significant and systematic influence on the cracking density. For both materials, the cracking density was dramatically reduced when the weld seam width at the top was increased, i.e., by slower welding speeds. From these results, it is evident that the width of the weld seam plays a key role in the crack formation of laser-welded grey cast iron with spheroidal graphite. A possible explanation for the described behavior is the fact that the weld seam volume is increased with high weld seam widths and, thus, more material volume is available to accommodate the stresses induced by the microstructural transformations and shrinkage during and after welding.

\subsection{Effect of Filler Material}

As can be seen in Figure 8, the crack density was substantially decreased for both, EN-GJS-400-15 and EN-GJS-700-2, with the use of nickel filler material. Notably, the use of nickel foil with a thickness of $0.250 \mathrm{~mm}$ enabled crack-free LBW of EN-GJS-700-2.

In combination with the macroscopic investigation of the weld seams in Figure 9, it is evident that weld seams underwent a different microstrucutral transformation due to the use of austenite-stabilizing nickel foil. When welded with foil of $0.125 \mathrm{~mm}$ thickness, zones of material segregation can be identified within the WM that probably developed due to the melt pool dynamics and subsequent transportation of nickel through the seam. 
(a)

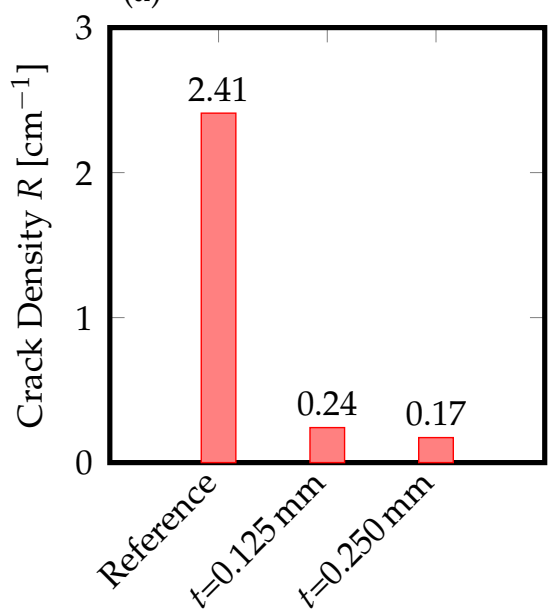

(b)

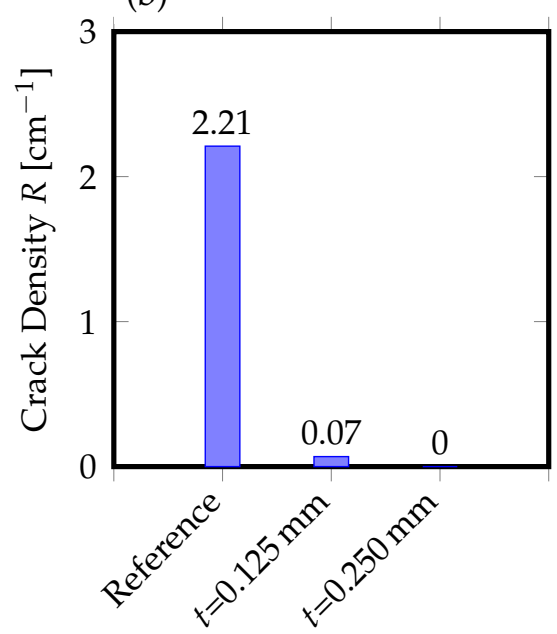

Figure 8. Comparison of crack density $R$ with different thicknesses of filler material and reference welds. (a) EN-GJS-400-15 and (b) EN-GJS-700-2. $P_{L}=6000 \mathrm{~W}, v_{L}=2.5 \mathrm{~m} \mathrm{~min}^{-1}$.
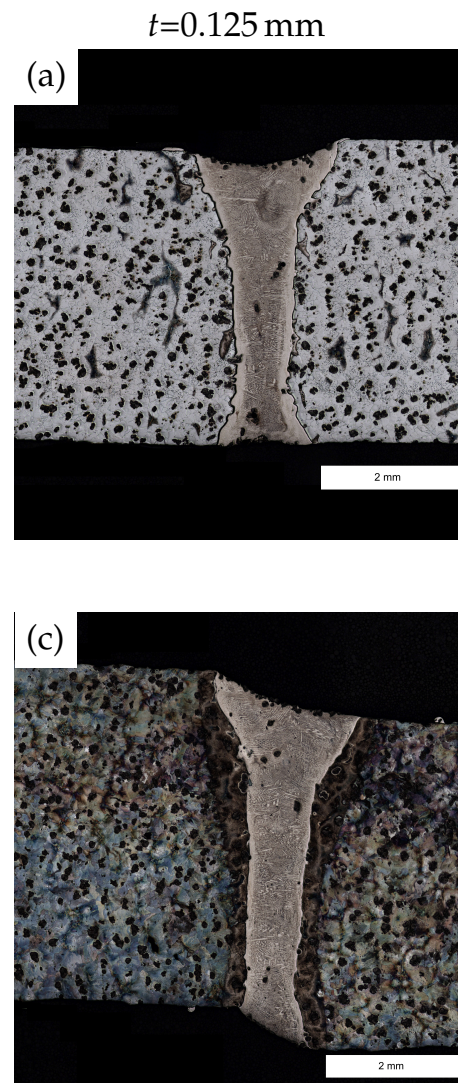
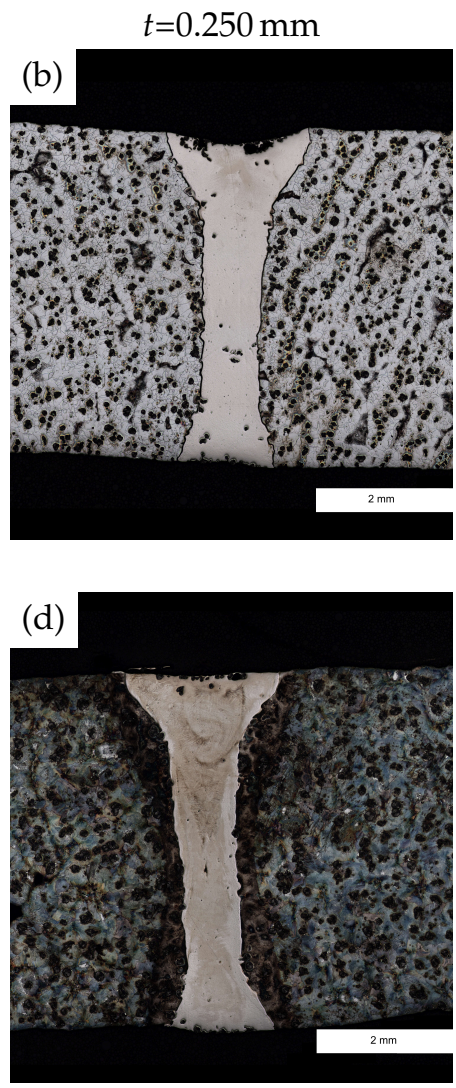

Figure 9. Macroscopic images of grey cast iron with spheroidal graphite welded by LBW using nickel filler material. (a,b) EN-GJS-400-15, (c,d) EN-GJS-700-2. $P_{L}=6000 \mathrm{~W}, v_{L}=2.5 \mathrm{~m} \mathrm{~min}^{-1}$.

In comparison to the results of the welding experiments conducted without filler material in Figure 3, the etchants reaction with the material was not as prominent. This indicated that more excess carbon could be accommodated in the face-centered cubic (fcc) matrix of the nickel material. With the use of a thickness of $0.250 \mathrm{~mm}$, the reaction of the etchant was even less, hinting at a dominantly nickel-based matrix with some segregations caused by melt pool dynamics. It was to be noted, however, that in samples of EN-GJS-700-2, a dominant HAZ—with presumably martensite-could be identified. 
In order to analyze the effect of nickel-containing filler material on the hardness, additional measurements, whose results are shown in Figure 10, were undertaken. From the results, it was evident that-in case of either thickness-a drastic reduction of hardness to around $450 \mathrm{HV}$ was achieved within the WM for both materials. This supports the theory that the fcc-phase of nickel enabled a farther accommodation of carbon and, thus, less hardening during welding. Yet, the hardness distribution of EN-GJS-700-2 hinted at another challenge within the HAZ. Despite the reduction of hardness within the WM, a drastic peak of hardness to up to $900 \mathrm{HV}$ could be observed in the HAZ of the latter. Obviously, the use of nickel filler material can drastically reduce the hardness of the WM, but it cannot prevent the solid state transformation of the microstructure within the HAZ to brittle phases such as martensite.
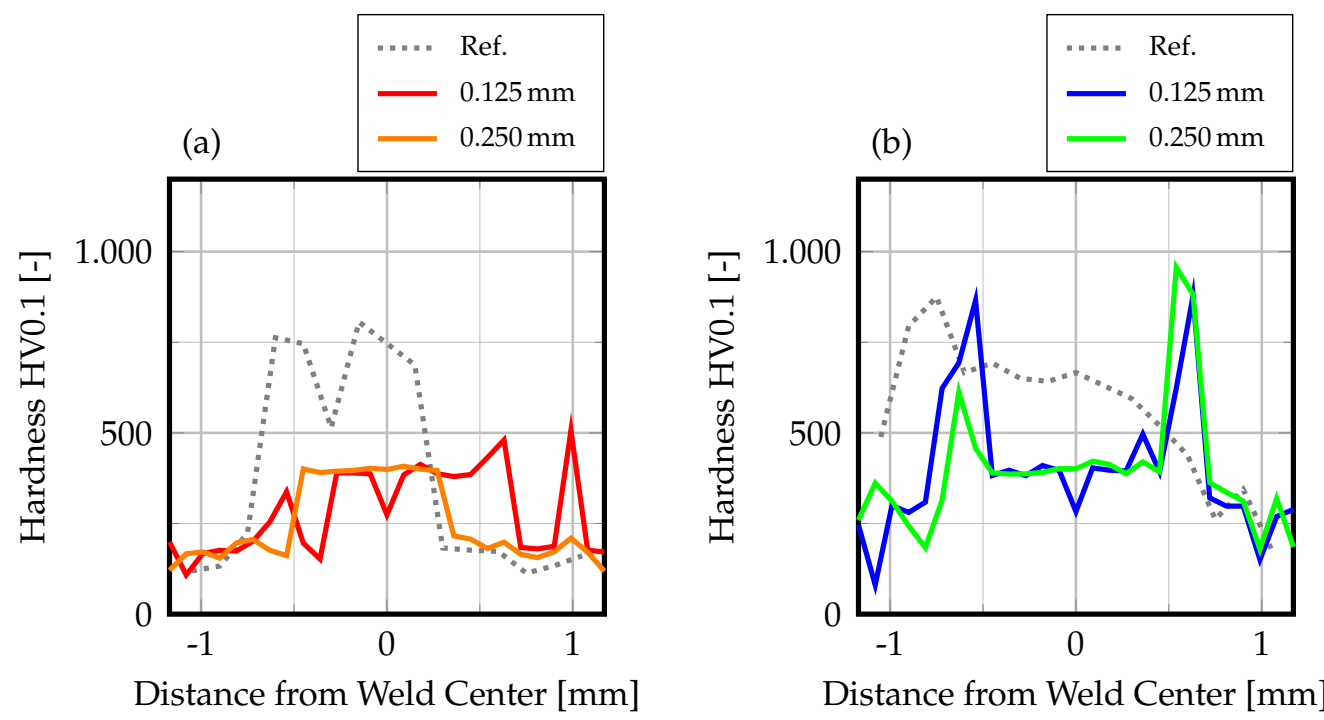

Figure 10. Hardness distribution across the weld seam of (a) EN-GJS-400-15 and (b) EN-GJS-7002 , welded with filler material of different thicknesses. $P_{L}=6000 \mathrm{~W}, v_{L}=2.5 \mathrm{~m} \mathrm{~min}^{-1}$. Reference adopted from samples welded without filler material.

Yet, in contrast to conventional welding processes described in the literature [5-7], it can be derived from the results that iron to iron welded joints can be produced with high welding speeds using LBW and additional filler material. On the other hand, the use of filler material is a reason for increased production cost in large-scale industrial welding applications.

\section{Conclusions}

From the results presented beforehand, a number of conclusions can be drawn:

- High-energy LBW of grey cast iron with spheroidal graphite leads to substantial crack formation on top of the weld seam with an increase of welding speed, reaching crack densities of up to $2.93 \mathrm{~cm}^{-1}$ and $2.44 \mathrm{~cm}^{-1}$ in EN-GJS-400-15 and EN-GJS-700-2, respectively.

- Due to rapid cooling and steep thermal gradients, the microstructure is transformed to ledeburite within the WM.

- EN-GJS-400-15 does not show a prominent HAZ, while EN-GJS-700-2 exhibits the formation of a HAZ with martensite and bainite.

- $\quad$ The crack density of both materials is strongly dependent on the weld seam width as weld seam widths of approximately $2000 \mu \mathrm{m}$ yield an almost doubled crack density when compared to weld seam widths of near $4000 \mu \mathrm{m}$

- The use of austenite-stabilizing filler material such as nickel-foil can alleviate cracking and reduce the hardness within the WM to maximum values of under $500 \mathrm{HV} 0.1$ for both materials. 
- Yet, the usage of nickel filler cannot hinder the hardness increase of the HAZ in EN-GJS-700-2, as it still reaches values of over 800 HV0.1.

The fact that an increase of weld seam width yielded a substantial decrease of crack density leads to the conclusion that further research should detail the possibilities of enlarged weld seam widths at high welding speeds, for example through the use of oscillating beam guidance optics. As the use of nickel filler material is associated with elevated production costs and cannot hinder the hardness increase in EN-GJS-700-2, other approaches such as the use of induction heating to manipulate the cooling cycle and, thus, microstructural transformation of the material are necessary, which were proposed by Vollmer et al. [13]. Evidently, more research efforts are required to enable crack-free LBW of grey cast iron with spheroidal graphite, cope with the simultaneous hardness increase and eliminate associated drawbacks.

Author Contributions: Conceptualization, N.S. and S.B.; methodology, N.S. and J.M.L.; validation, N.S., J.M.L. and S.B.; formal analysis, J.M.L., N.S. and S.V.; investigation, N.S. and J.M.L.; resources, N.S. and S.V.; data curation, N.S. and J.M.L.; writing-original draft preparation, N.S.; writingreview and editing, S.V. and S.B.; visualization, N.S.; supervision, S.B.; project administration, N.S.; funding acquisition, S.V. and S.B. All authors have read and agreed to the published version of the manuscript.

Funding: The shown results were achieved in the project "Laserstrahlschweißen von Gusseisen mit induktiver Temperaturführung und oszillierender Strahlführung" (reference IGF 20.070N), which is supervised by the Forschungsvereinigung Schweißen und verwandte Verfahren e.V. of the German Welding Society and funded by the German Federation of Industrial Research Associations (AiF) by means of the Federal Ministry of Economic Affairs and Energy (BMWi) on the basis of a decision by the German Bundestag.

Institutional Review Board Statement: Not applicable.

Informed Consent Statement: Not applicable.

Data Availability Statement: The data presented in this study are available on reasonable request from the corresponding author. The data are not publicly available due to the fact that the data are part of an ongoing investigation.

Acknowledgments: The authors would like to thank Josef Schonlau, Maschinenfabrik und Eisengießerei $\mathrm{GmbH} \& \mathrm{Co}$. KG (Geseke, Germany) for providing the cast iron material used in the investigation.

Conflicts of Interest: The authors declare no conflict of interest. The funders had no role in the design of the study; in the collection, analyses, or interpretation of data; in the writing of the manuscript, or in the decision to publish the results.

\begin{tabular}{|c|c|}
\hline \\
\hline \multicolumn{2}{|c|}{$\begin{array}{l}\text { Abbreviations } \\
\text { The following abbreviations are us }\end{array}$} \\
\hline$A_{L}$ & area of laser beam, $\left[\mathrm{cm}^{2}\right]$ \\
\hline AOI & area of interest \\
\hline $\mathrm{C}$ & carbon \\
\hline$E_{L}$ & energy input, $\left[\mathrm{J} \mathrm{mm}^{-1}\right]$ \\
\hline fcc & face-centered cubic \\
\hline $\mathrm{Fe}$ & iron \\
\hline HAZ & heat-affected zone \\
\hline$I_{L}$ & laser intensity, [ $\mathrm{W} \mathrm{cm}^{-2}$ ] \\
\hline$l$ & weld seam length, [cm] \\
\hline LBW & laser beam welding \\
\hline Mn & manganese \\
\hline$n_{R}$ & number of cracks, [-] \\
\hline $\mathrm{OM}$ & optical microscopy \\
\hline $\mathrm{P}$ & phosphorus \\
\hline
\end{tabular}




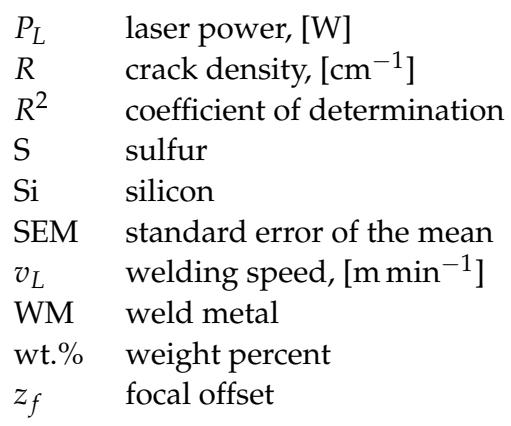

\section{References}

1. Keough, J.R.; Hayrynen, K.L. Automotive Applications of Austempered Ductile Iron (ADI): A Critical Review. SAE Trans. 2000, 244-354.

2. Dilthey, U. Schweißtechnische Fertigungsverfahren 2: Verhalten der Werkstoffe beim Schweißen, 3rd ed.; Bearbeitete Auflage Ed.; VDI-Buch; Springer: Berlin/Heidelberg, Germany, 2005. [CrossRef]

3. Forsström, A.; Yagodzinskyy, Y.; Hänninen, H. Hydrogen effects on mechanical performance of nodular cast iron. Corros. Rev. 2019, 37, 441-454. [CrossRef]

4. Sahiluoma, P.; Yagodzinskyy, Y.; Forsström, A.; Hänninen, H.; Bossuyt, S. Hydrogen embrittlement of nodular cast iron. Mater. Corros. 2021, 72, 245-254. [CrossRef]

5. Askari-Paykani, M.; Shayan, M.; Shamanian, M. Weldability of Ferritic Ductile Cast Iron Using Full Factorial Design of Experiment. J. Iron Steel Res. Int. 2014, 21, 252-263. [CrossRef]

6. Voigt, R.C.; Loper, C.R. A Study of Heat-Affected Zone Structures in Ductile Cast Iron; WRC: Shaker Heights, OH, USA, 1983.

7. Pascual, M.; Cembrero, J.; Salas, F.; Martínez, M.P. Analysis of the weldability of ductile iron. Mater. Lett. 2008, 62, 1359-1362. [CrossRef]

8. Rüthrich, K.; Zenker, R.; Mangler, M. Untersuchungen zum Elektronenstrahl-Mehrbadschweißen von Gusseisen in Verbindung mit Thermofeldern. DVS-Berichte 2011, 275, 113-121.

9. Rüthrich, K.; Mangler, M. Elektronenstrahl-Mehrprozesstechnik - Schweißen mit integrierter Wärmebehandlung. HTM J. Heat Treat. Mater. 2012, 67, 22-30. [CrossRef]

10. Rüthrich, K. Beitrag zur Entwicklung des Elektronenstrahl-Mehrspot/Mehrprozess-Schweißens von Gusseisen/Gusseisen- und Gusseisen/Stahl-Verbindungen ohne Schweißzusatzstoffe. Ph.D. Thesis, Technische Universität Bergakademie Freiberg, Freiberg, Germany, 2014.

11. Bünting, A.; Francke, S. Laserstrahlschweißen von Gusseisen und Einsatzstahl ohne Zusatzwerkstoff. DVS-Berichte 2010, $212-214$.

12. Yu, J.; Jung, T.; Kim, S.; Rhee, S. Laser welding of cast iron and carburized steel for differential gear. J. Mech. Sci. Technol. 2011, 25, 2887-2893. [CrossRef]

13. Vollmer, M.; Mienert, G.; Fehlbier, M.; Böhm, S.; Niendorf, T. Induction-assisted laser beam welding of cast iron materials Microstructure and mechanical properties. Weld. Cut. 2017, 16, 316-320.

14. Saffer, J.; Dörres, T.; Schaumberger, K.; Ermer, J.; Kaufmann, F.; Wittmann, A.; Roth, S.; Schmidt, M. Laser beam welding of heat-resistant mixed joints using laser-based pre- and post-heating. Procedia CIRP 2020, 94, 671-675. [CrossRef]

15. Janicki, D. Direct Diode Laser Surface Melting of Nodular Cast Iron. Appl. Mech. Mater. 2015, 809-810, 423-428. [CrossRef]

16. Janicki, D.; Górka, J.; Kwaśny, W.; Pakieła, W.; Matus, K. Influence of Solidification Conditions on the Microstructure of Laser-Surface-Melted Ductile Cast Iron. Materials 2020, 13, 1174. [CrossRef] [PubMed]

17. Janicki, F. Fabrication of High Chromium White Iron Surface Layers on Ductile Cast Iron Substrate by Laser Surface Alloying Stroj. Vestn. J. Mech. Eng. 2017, 63, 705-714 [CrossRef]

18. Litfin, G. Technische Optik in der Praxis (German Edition); Springer: Dordrecht, The Netherland, 2005.

19. Dilthey, U. Schweißtechnische Fertigungsverfahren 1: Schweiß-und Schneidtechnologien, 3rd ed.; Bearbeitete Auflage Ed.; VDI-Buch; Springer: Berlin/Heidelberg, Germany, 2006. [CrossRef]

20. Deutsches Institut für Normung e.V. Zerstörungsfreie Prüfung Eindringprüfung: Teil 1: Allgemeine Grundlagen (ISO/DIS 3452-1:2019); Deutsche und Englische Fassung prEN ISO 3452-1:2019; Deutsches Institut für Normung e.V.: Koblenz, Germany, 2020.

21. Deutsches Institut für Normung e.V. Metallische Werkstoffe - Härteprüfung nach Vickers: Teil 1: Prüfverfahren (ISO 6507-1:2018); Deutsche Fassung EN ISO 6507-1:2018; Deutsches Institut für Normung e.V.: Koblenz, Germany, 2018. 